Original Article

\title{
Disgust and mating strategy
}

\author{
Laith Al-Shawaf a,*, David M.G. Lewis ${ }^{\text {b }}$, David M. Buss ${ }^{\text {a }}$ \\ a Department of Psychology, The University of Texas at Austin, 1 University Station A8000, Austin, TX 78712, USA \\ b Department of Psychology, Bilkent University, 06800 Bilkent, Ankara, Turkey
}

\section{A R T I C L E I N F O}

\section{Article history:}

Initial receipt 3 April 2014

Final revision received 6 November 2014

\section{Keywords:}

Disgust

Human mating

Sexual behavior

Mating strategies

SOI

Physical attractiveness

\begin{abstract}
A B S T R A C T
An evolutionary task analysis predicts a connection between disgust and human mating, two important but currently disconnected areas of psychology. Because short-term mating strategies involve sex with multiple partners after brief temporal durations, such a strategy should be difficult to pursue in conjunction with high levels of sexual disgust. On this basis, we hypothesized that individuals with a stronger proclivity for shortterm mating would exhibit dispositionally lower levels of sexual disgust. Two independent studies provided strong support for this hypothesis: among both men and women, an orientation toward short-term mating was associated with reduced levels of sexual disgust, but not with suppressed moral or pathogen disgust. Our discussion highlights an unexpected finding and suggests important questions for future research.
\end{abstract}

(c) 2015 Elsevier Inc. All rights reserved.

\section{Introduction}

Research programs on the emotion of disgust and the psychology of mating have produced a wealth of empirical findings relevant to the study of cognition, emotion, individual differences, social relationships, and sexual behavior (Al-Shawaf \& Lewis, 2013; Angyal, 1941; Buss, 2003, 2012; Curtis, de Barra, \& Aunger, 2011; Fleischman \& Fessler, 2011; Gangestad \& Simpson, 2000; Haidt, McCauley, \& Rozin, 1994; Navarrete \& Fessler, 2006; Rozin \& Fallon, 1987; Schaller, Miller, Gervais, Yager, \& Chen, 2010; Tybur, Lieberman, Kurzban, \& DeScioli, 2012). Despite successes in the fields of disgust and mating, these domains of research remain largely disconnected (for exceptions, see Borg \& de Jong, 2012; Fleischman, 2014; Lee, Dubbs, Von Hippel, Brooks, \& Zietsch, 2014; Tybur \& Gangestad, 2011).

Extant research on the relationship between disgust and mating has made valuable contributions to understanding the relationship between disgust and the temporary state of sexual arousal (e.g. de Jong, van Overveld, \& Borg, 2013; Fleischman, 2014; Stevenson, Case, \& Oaten, 2011). This research has shown, for example, that sexually aroused individuals experience temporarily suppressed disgust in response to otherwise sexually repellent stimuli (Stevenson et al., 2011); that sexual arousal increases reported willingness to engage in sexual behaviors that might otherwise be disgusting (Ariely \& Loewenstein, 2006), and that sexually aroused women are less disgusted by, and less avoidant of, typically disgust-inducing stimuli and tasks (Borg \& de Jong, 2012). These studies have made important contributions to arousal and disgust

\footnotetext{
* Corresponding author. Tel.: +1 5125477735.

E-mail address: laith.alshawaf@mail.utexas.edu (L. Al-Shawaf).
}

research, but have focused almost exclusively on immediate, state-level disgust and state-level sexual arousal.

This paper seeks to complement this emphasis and fill this research gap by investigating the relationship between dispositional, trait-level aspects of disgust and human mating. This report provides a cogent theoretical rationale for an important link between these domains, advances a novel hypothesis about the relationship these two aspects of human psychology, and supports the hypothesized connection with two independent studies.

Early research by Haidt and colleagues made groundbreaking strides in studying the emotion of disgust, its elicitors, and individual differences in its thresholds, as well as constructing a scale with which to measure the emotion (Haidt et al., 1994; Rozin \& Fallon, 1987). However, this important foundational work presented a statistically and conceptually problematic analysis of the different types of disgust, most notably by arguing for the existence of a subtype of disgust called "animal reminder" disgust (Haidt et al., 1994; for thorough discussions of the limitations of the Disgust Scale, see Al-Shawaf \& Lewis, 2013; Fessler \& Navarrete, 2005; Tybur, Lieberman, \& Griskevicius, 2009, Tybur et al., 2012).

Recent research has identified three distinct types of disgust that are demarcated along different lines: pathogen, sexual, and moral disgust (Tybur et al., 2009, 2012). These forms of disgust are differentiated by the cues that elicit them, the behaviors that they motivate, and their distinct profiles of correlations with other psychological variables (Tybur et al., 2012). In this paper, we focus on sexual disgust, an emotion that has been hypothesized to "reduce participation in biologically suboptimal sexual behaviors" (Fessler \& Navarrete, 2003, p. 406).

These pioneering researchers have emphasized this emotion's function in preventing individuals from making injudicious mating decisions with unsuitable sexual partners (Fessler \& Navarrete, 2003; Tybur et al., 2012). Here, we further elaborate this valuable idea by 
showing how this emotion may be adaptively calibrated in the opposite direction; sexual disgust may be strategically and functionally downregulated to facilitate the successful pursuit of mating.

\subsection{Mating strategy and sexual disgust}

Individuals vary in mating strategy-their disposition toward longterm, committed mateships versus short-term, uncommitted mateships (Buss \& Schmitt, 1993; Gangestad \& Simpson, 1990, 2000). Different mating strategies present distinct adaptive challenges, which in turn lead to the evolution of strategy-specific psychological and behavioral solutions. A task analysis (Marr, 1982) of these distinct challenges identifies the problems individuals must solve to successfully implement different mating strategies and leads to hypotheses about the psychological solutions that could have evolved to solve these adaptive problems.

Successful short-term mating strategies typically involve multiple sex partners, desire for sexual variety, and brief intervals of time before sexual intercourse (Buss, 2012). This strategy should be difficult to implement in the presence of high levels of sexual disgust: individuals with high levels of sexual disgust are less likely to be comfortable with casual sex, multiple partners, and sex that occurs before sufficient information can be acquired about the health and hygiene status of potential mates. Consequently, we propose that a crucial component of a successful short-term mating strategy is the downregulation of sexual disgust sensitivity. On this hypothesis, suppressed levels of sexual disgust may be a previously undiscovered design feature of short-term mating strategies.

In contrast, down-regulated sexual disgust is not necessary for the successful pursuit of a monogamous strategy. In fact, higher levels of sexual disgust may facilitate the implementation of committed mating strategies by inhibiting short-term mating and deterring those in committed relationships from sexual infidelity.

This reasoning suggests that sexual disgust should be dispositionally lower among individuals pursuing a short-term mating strategy relative to those pursuing committed mating. We therefore hypothesized that mating strategy calibrates sexual disgust. Specifically, we predicted that a stronger disposition toward short-term mating is associated with reduced sexual disgust sensitivity.

\subsection{Mating strategy and physical attractiveness}

This task analysis suggests a link between mating strategy and sexual disgust, but leaves a different question unanswered: Why do some individuals exhibit a stronger orientation toward short-term mating than others? Theory and research suggest that the answer lies partly in individual differences in physical attractiveness (Gangestad \& Simpson, 2000; Rhodes, Simmons, \& Peters, 2005).

Women shoulder the greater minimum obligatory investment in offspring and thereby incur more severe costs from injudicious mating decisions (Trivers, 1972). Consequently, women have evolved more discriminating mate preferences (Buss, 2003; Trivers, 1972). This sex difference in choosiness is particularly pronounced in the context of short-term mating, which carries greater potential costs for women than for men (Symons, 1979; Trivers, 1972). For example, women face the potential of a costly nine-month pregnancy (Trivers, 1972), are at greater risk of contracting sexually transmitted diseases, and suffer more severe reproductive consequences as a result of these diseases (National Center for HIV/AIDS, Viral Hepatitis, STD, and TB Prevention, 2011).

A female-biased sex difference in the costs of short-term mating is mirrored by a male-biased sex difference in the benefits: ancestrally, success in short-term mating paid greater fitness dividends to men than to women. A large body of research demonstrates that both sexes share a complex repertoire of evolved mating strategies (Buss \& Schmitt, 1993), and that there is substantial within-sex variability in mating strategies (Gangestad \& Simpson, 1990, 2000). Nonetheless, abundant empirical evidence from dozens of data sources shows that short-term mating looms larger in men's than in women's mating psychology (Buss, 2012; Buss \& Schmitt, 1993) and is pursued more vigorously by men (Lippa, 2009).

Because physical attractiveness is desirable in a mate (Sugiyama, 2005; Symons, 1979, 1995) and enhances one's mate value (Buss, 2003), physically attractive individuals should be better able to implement their preferred mating strategy. And because successful shortterm mating strategies were more reproductively beneficial for men than women during human evolution (Buss, 2003; Symons, 1979), evolutionary reasoning suggests that physical attractiveness should lead men-but not women-to pursue uncommitted mating.

Researchers have shown that in men, but not women, physical attractiveness and related indices such as fluctuating asymmetry predict number of sex partners, number of affair partners, and other measures of short-term mating (Gangestad \& Simpson, 2000; Rhodes et al., 2005). This pattern is mirrored in other species: more attractive male birds devote less effort to parenting when they can translate their physical attractiveness into extra-pair copulations (Johnsen, Delhey, Schlicht, Peters, \& Kempenaers, 2005; Møller, 1994; Møller \& Thornhill, 1998).

Precisely how physical attractiveness leads to larger numbers of short-term mates remains unknown, however. Extant findings link physical attractiveness to behavioral outcomes such as number of sex partners, but have not assessed whether physically attractive men experience greater activation of underlying short-term mating psychology. The link between physical attractiveness and mating could, in principle, occur via a change in behavior alone or via a shift in both behavior and psychology. Consequently, we sought to replicate this link between male physical attractiveness and shortterm mating and investigate whether it applies to underlying psychology as well as manifest behavior.

\subsection{The current study}

We propose a two-step process in which physical attractiveness calibrates mating strategy and mating strategy calibrates sexual disgust. The first part of this model is sex-differentiated, with physical attractiveness leading to uncommitted mating in men but not women. The second part of this model posits the same relationship for both sexes, with a disposition toward short-term mating leading to reduced levels of sexual disgust sensitivity in both men and women.

\section{Study 1}

\subsection{Methods}

\subsubsection{Participants and procedure}

One hundred forty-four women and 103 men $\left(M_{\mathrm{age}}=19.49\right.$ years, $S D_{\text {age }}=2.56$, age range $=18-51$ ) were recruited from the psychology subject pool at The University of Texas at Austin. Participants arrived at the laboratory, provided informed consent to participate in the study, and were escorted by a researcher to a private room where they completed an online survey hosted by Qualtrics. Participants received partial course credit for their participation and were debriefed upon completion.

\subsubsection{Measures}

As part of a larger study on individual differences in disgust sensitivity, participants completed a set of inventories designed to measure mating strategy, physical attractiveness, and disgust.

2.1.2.1. Mating strategy. We operationalized mating strategy with the Revised Sociosexual Orientation Inventory (SOI-R; Penke \& Asendorpf, 2008). This enabled us to measure both psychological and behavioral facets of short-term mating; the SOI-R is a nine-item measure of an 
individual's behavioral, cognitive, and attitudinal disposition toward uncommitted sexual relations. Sample items include "With how many different partners have you had sex within the past 12 months?" (behavior), "How often do you experience sexual arousal when you are in contact with someone you are not in a committed romantic relationship with?" (desire), and "I can imagine myself being comfortable and enjoying "casual' sex with different partners" (attitude). Inventory items are summed to form a composite SOI-R score, with higher scores reflecting a stronger disposition toward short-term mating.

2.1.2.2. Physical attractiveness. We assessed participants' physical attractiveness with the International Personality Item Pool physical attractiveness scale (Goldberg et al., 2006). We elected to use this selfreport measure because individuals have direct access to selfrepresented attractiveness, but not "objective" ratings of attractiveness. The information-processing mechanisms responsible for calibrating mating strategy are therefore expected to operate on self-represented attractiveness, an internal regulatory variable whose value is likely based on multiple sources of information across time (for a discussion of internal regulatory variables, see Lieberman, Tooby, \& Cosmides, 2007; Tooby, Cosmides, Sell, Lieberman, \& Sznycer, 2008). Sample items on the nine-item Likert-type scale include "Have a pleasing physique" and "Attract attention from the opposite sex."

2.1.2.3. Disgust. We measured disgust with the Three Domain Disgust Scale (TDDS), a 21-item instrument composed of three seven-item subscales designed to assess pathogen, sexual, and moral disgust (Tybur et al., 2009). The TDDS asks participants to rate how disgusting they find a variety of potentially repellent situations on a 7-point Likerttype scale $(0=$ not at all disgusting, $6=$ extremely disgusting). Sample items from the sexual disgust subscale include "A stranger of the opposite sex intentionally rubbing your thigh in an elevator" and "Performing oral sex."

We measured all three forms of disgust to determine whether the proposed link between mating strategy and disgust is specific to the sexual domain or permeates other facets of disgust as well. Although our central hypothesis is consistent with either outcome, our a priori reasoning pertains specifically to sexual disgust. Demonstrating the specificity of the link between mating strategy and sexual disgust would therefore provide more discriminating empirical support for the rationale underlying our hypothesis.

\subsection{Results}

We tested study hypotheses with two different analytic methods. First, zero-order correlations and regression analyses were used to test the predicted relationships between (i) physical attractiveness and mating strategy and (ii) mating strategy and sexual disgust. Second, we conducted exploratory path analyses in which we investigated the possibility of an indirect effect of physical attractiveness on sexual disgust via mating strategy.

\subsubsection{Descriptive statistics}

Table 1 presents means and standard deviations for the three disgust scales (Cronbach's $\alpha$ : moral $=.87$, sexual $=.86$, pathogen $=.80$ ) and the sociosexual orientation inventory $(\alpha=.68)$.

Sex differences in disgust followed a similar pattern to those reported by Tybur and colleagues $(2009,2012)$. Consistent with previous research, women in the current study exhibited stronger pathogen disgust $[t(241)=-3.31, p<.001]$ and sexual disgust $[t(245)=$ $-11.99, p<.001]$. Whereas Tybur and coworkers $(2009,2011)$ found stronger female disgust in all three domains, the effect for moral disgust did not reach significance in the current study $[t(242)=-1.37, n s]$. More broadly, these findings replicate the reliable sex difference demonstrated in much of the disgust literature over the last several decades: women exhibit significantly higher levels of disgust than men
Table 1

Means, standard deviations, and effect sizes for the sex difference in study 1 .

\begin{tabular}{llll}
\hline Disgust subscale (TDDS) & Men mean (SD) & Women mean (SD) & Cohen's $d$ \\
\hline Sexual & $22.85(8.57)$ & $35.53(7.90)$ & $1.54^{* * *}$ \\
Moral & $32.89(9.43)$ & $34.50(8.81)$ & .18 \\
Pathogen & $32.99(7.28)$ & $36.17(7.41)$ & $.43^{* *}$ \\
Mating Strategy (SOI-R) & & & \\
Sociosexual orientation & $38.80(14.59)$ & $23.76(11.30)$ & $1.15^{* * *}$ \\
\hline${ }^{*} p<.05$. & & & \\
$* * * .01$. & & & \\
$* * *$ & $p<.001$.
\end{tabular}

(e.g., Al-Shawaf \& Lewis, 2013; Curtis, Aunger, \& Rabie, 2004; Haidt et al., 1994; Fessler, Pillsworth, \& Flamson, 2004; Tybur et al., 2009).

\subsubsection{Mating strategy and sexual disgust}

Our primary hypothesis suggests that short-term mating should be associated with reduced levels of sexual disgust in both sexes. As predicted, short-term mating was inversely related to sexual disgust, and this effect was independent of sex [men: $r(97)=-.44, p<.001$; women: $r(136)=-.46, p<.001$; sex*SOI-R interaction: $\beta=-.109$, $t(233)=-.74, n s$.] (Fig. 1, top panel).

Moreover, this relationship between mating strategy and disgust was specific to the sexual domain; mating strategy was not associated with individual differences in moral disgust [men: $r(96)=-.07, n s$; women: $r(134)=-.12, n s$ ] or pathogen disgust [men: $r(97)=-.01$, $n s$; women: $r(135)=-.16, n s]$.

To ensure that the relationship between mating strategy and sexual disgust was not merely due to content overlap between the instruments measuring the two constructs, we re-ran the same analyses after removing items of potential overlap from the sexual disgust scale
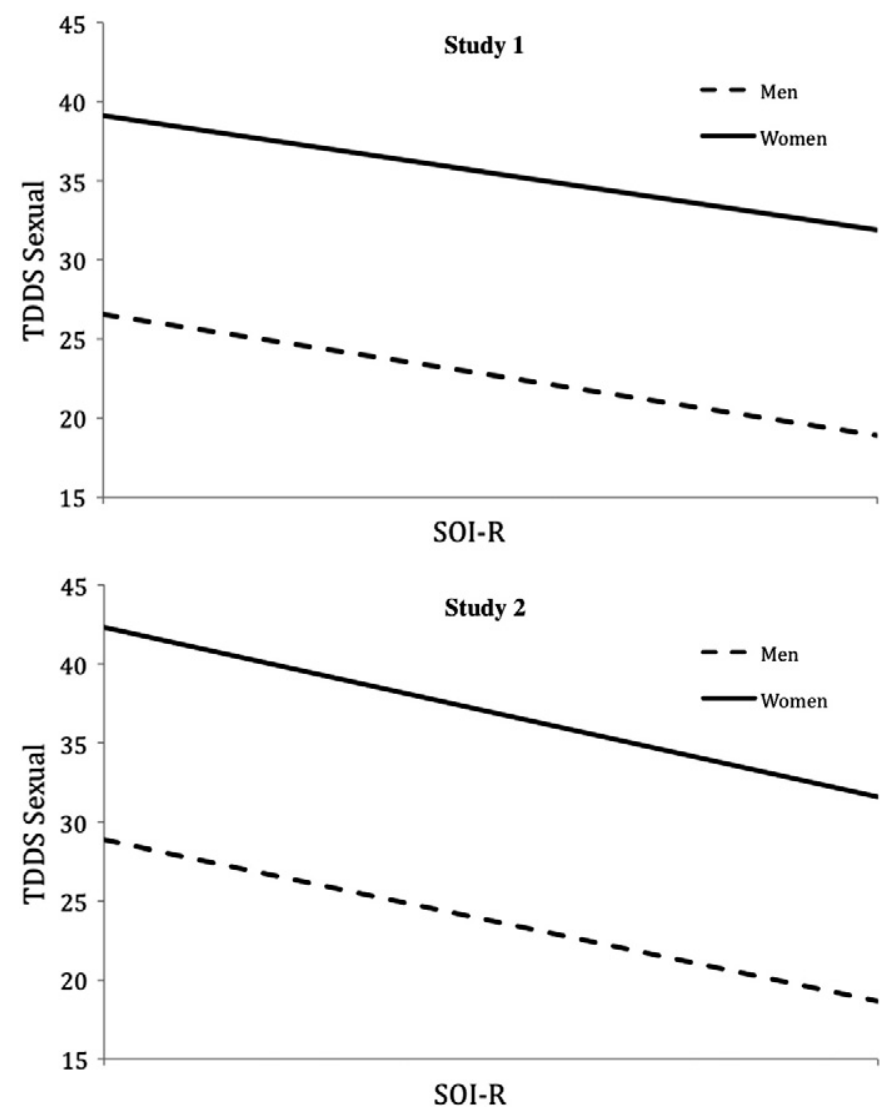

Fig. 1. Mating strategy predicts disgust. Lines represent model-predicted values. Shortterm mating is inversely related to sexual disgust in both men (dashed line) and women (solid line). 
(specifically, items 11, 14, and 17 of the TDDS). Short-term mating was still inversely related to sexual disgust [men: $r(97)=-.34, p<.001$, women: $r(136)=-.29, p<.001]$, and this effect was still independent of sex [sex*SOI-R interaction: $\beta=-.028, t(233)=-.16, n s]$. The fact that these analyses yielded the same substantive results, without exception, unambiguously indicates that the relationship between mating strategy and sexual disgust is not an artifact of instrument overlap.

\subsubsection{Mating strategy and physical attractiveness}

Our secondary hypothesis was that physical attractiveness would be associated with short-term mating disposition among men but not women. Regression analyses supported this hypothesis: physical attractiveness and sex interacted to predict individuals' SOI scores, $\beta=$ $-.657, t(228)=-2.189, p=.03$. As predicted, men's inclination toward short-term mating correlated positively with their physical attractiveness, $r(95)=.25, p=.01$, whereas women's physical attractiveness was not associated with the pursuit of short-term mating, $r(133)=.00, n s$.

\subsubsection{Physical attractiveness $->$ mating strategy $->$ sexual disgust}

The links observed between a) men's attractiveness and mating strategy, and b) men's mating strategy and sexual disgust, raise the question: is there an indirect link between men's physical attractiveness and sexual disgust via mating strategy? To answer this question, we used a path analysis to model the indirect pathway from men's attractiveness to sexual disgust through mating strategy (Mplus, version 7).

Modeling this relationship revealed an indirect path from men's physical attractiveness to their sexual disgust via mating strategy, $\beta=$ $-.12, S E=.05, p=.02$ (Fig. 2). Among women, on the other hand, there was no indirect path from physical attractiveness to sexual disgust, $\beta=.00, S E=.04, n s$, consistent with the absence of a relationship between women's physical attractiveness and mating strategy.

\section{Study 2}

To provide a more stringent test of our hypotheses, we subjected our findings to a reproducibility test in a second study with an independent sample.

\subsection{Method}

Two hundred and three women and eighty men $\left(M_{\text {age }}=18.89\right.$ years, $S D_{\text {age }}=2.81$, age range $=18-50$ ) were recruited from the psychology subject pool at The University of Texas at Austin. One participant did not indicate his/her gender and was therefore excluded from analyses. Participants received partial course credit for participation, and completed the same set of materials as those described in study 1 .

\subsection{Results}

\subsubsection{Descriptive statistics}

Table 2 presents means and standard deviations for the three disgust scales (Cronbach's $\alpha$ : moral $=0.86$, sexual $=0.88$, pathogen $=0.83$ ) and the sociosexual orientation inventory ( $\alpha$ : 0.65$)$. Sex differences in disgust were similar to those obtained in study 1 and in Tybur et al.'s seminal studies, with women exceeding men in all three domains of disgust [moral: $t(277)=-2.55, p<.05$, pathogen: $t(277)=-4.73$, $p<.001$, sexual: $t(278)=-11.00, p<.001]$.

\subsubsection{Mating strategy and sexual disgust}

Replicating study 1 's findings and providing strong confirmatory evidence for our primary hypothesis, short-term mating was associated with down-regulated sexual disgust [men: $r(76)=-.51, p<.001$; women: $r(190)=-.61, p<.001]$, and this effect was independent of sex; sex*SOI-R interaction: $\beta=-.174, t(266)=-1.151$, ns (Fig. 1, bottom panel).

\section{MEN}

\begin{tabular}{|c|c|c|c|c|}
\hline \multirow{2}{*}{$\begin{array}{c}\text { Physical } \\
\text { Attractiveness } \\
\text { (IPIP) }\end{array}$} & Study $1: \beta=.25, p<.01$ & \multirow{2}{*}{$\begin{array}{c}\text { Short-Term Mating } \\
\text { (SOI-R) }\end{array}$} & Study $1: \beta=-.49, p<.001$ & \multirow{2}{*}{$\begin{array}{l}\text { Sexual Disgust } \\
\text { (TDDS Sexual) }\end{array}$} \\
\hline & Study $2: \beta=.39, p<.001$ & & Study $2: \beta=-.51, p<.001$ & \\
\hline
\end{tabular}

Indirect effect

Study 1: $\beta=-.12, p=.02$

Study $2: \beta=-.20, p=.001$

\section{WOMEN}

\begin{tabular}{|c|c|c|c|c|}
\hline \multirow{2}{*}{$\begin{array}{c}\text { Physical } \\
\text { Attractiveness } \\
\text { (IPIP) }\end{array}$} & Study $1: \beta=.00, p=.99$ & \multirow{2}{*}{$\begin{array}{c}\text { Short-Term Mating } \\
\text { (SOI-R) }\end{array}$} & Study $1: \beta=-.45, p<.001$ & \multirow{2}{*}{$\begin{array}{l}\text { Sexual Disgust } \\
\text { (TDDS Sexual) }\end{array}$} \\
\hline & Study $2: \beta=.17, p=.02$ & & Study $2: \beta=-.61, p<.001$ & \\
\hline
\end{tabular}

\section{Indirect effect}

Study $1: \beta=.00, p=.99$

Study $2: \beta=-.10, p=.02$ 
Table 2

Means, standard deviations, and effect sizes for the sex difference in study 2 .

\begin{tabular}{lllc}
\hline Disgust subscale (TDDS) & Men mean (SD) & Women mean (SD) & Cohen's $d$ \\
\hline Sexual & $23.76(9.91)$ & $37.05(8.79)$ & $1.42^{* * *}$ \\
Moral & $32.17(10.05)$ & $35.19(8.42)$ & $.33^{*}$ \\
Pathogen & $31.96(8.49)$ & $36.92(7.61)$ & $.62^{* * *}$ \\
Mating strategy (SOI-R) & & & \\
Sociosexual orientation & $38.14(14.71)$ & $23.12(12.48)$ & $1.10^{* * *}$ \\
\hline$* p<.05$. & & & \\
$* * \quad p<.01$. & & \\
$* * * \quad p<.001$. & & & \\
$*$ & &
\end{tabular}

As in study 1 , the link between mating strategy and disgust was specific to the sexual domain. Among both men and women, short-term mating was not associated with moral disgust [men: $r(75)=.01$, $n s$; women: $r(191)=-.11, n s]$ or pathogen disgust [men: $r(74)=.02, n s$; women: $r(191)=-.11, n s]$.

As in study 1, we re-ran these analyses to ensure that the relationship between mating strategy and sexual disgust was not merely due to instrument overlap. We again found the same substantive results, without exception. Short-term mating was inversely related to sexual disgust [men: $r(76)=-.48, p<.001$, women: $r(190)=-.56$, $p<.001$ ], and this effect was again independent of sex [sex*SOI-R interaction: $\beta=-.266, t(266)=-1.573, n s]$.

In sum, across four possible analyses (two independent studies, each analyzed using both the original scales and the scales after removing items of potentially overlapping content), we found the same substantive results without exception. A disposition for short-term mating is associated with reduced levels of sexual disgust, but not with pathogen or moral disgust.

\subsubsection{Mating strategy and physical attractiveness}

Replicating study 1 's findings, and consistent with our secondary hypothesis that physical attractiveness has differential effects on men's and women's short-term mating psychology, physical attractiveness and sex interacted to predict individuals' SOI scores, $\beta=-.67$, $t(266)=-2.23, p=.03$. As predicted, men's inclination toward short-term mating was positively associated with their physical attractiveness, $r(76)=.38, p=.001$. Unexpectedly, however, women's attractiveness also exhibited a small positive correlation with their SOI-R scores, $r(190)=.15, p=.03$. Tables 3 and 4 display zero-order bivariate correlations between physical attractiveness and each subscale of the SOI-R for both men and women.

\subsubsection{Physical attractiveness $\rightarrow$ mating strategy $\rightarrow$ sexual disgust}

Study 2's replication of the observed relationships between men's attractiveness, mating strategy, and sexual disgust again suggested the possibility of an indirect relationship between men's attractiveness and sexual disgust through their mating strategy. Replicating the same link observed in study 1 , study 2 data revealed an indirect path from men's attractiveness to their sexual disgust via mating strategy, $\beta=-.20, S E=.06, p=.001$.

Table 3

Correlations between men's physical attractiveness and short-term mating.

\begin{tabular}{lll}
\hline Sociosexual Orientation Inventory-Revised (SOI-R) & Study 1 & Study 2 \\
\hline Behavior & $.33^{* *}$ & $.42^{* *}$ \\
Attitude & .14 & $.35^{* *}$ \\
Desire & .16 & .16 \\
Overall & $.25^{*}$ & $.38^{* *}$ \\
\hline
\end{tabular}

$* p<.05$

$* * p<.01$
Table 4

Correlations between women's physical attractiveness and short-term mating.

\begin{tabular}{lcl}
\hline Sociosexual Orientation Inventory-Revised (SOI-R) & Study 1 & Study 2 \\
\hline Behavior & $.20^{*}$ & $.24^{* *}$ \\
Attitude & -.08 & .13 \\
Desire & .01 & .07 \\
Overall & .00 & $.15^{*}$ \\
\hline
\end{tabular}

$* p<.05$.

$* * \quad p<.01$.

\section{Discussion}

\subsection{Mating strategy and sexual disgust}

Our primary hypothesis was that a stronger disposition toward short-term mating would be associated with reduced sexual disgust sensitivity among both men and women. This hypothesis received strong support. In both studies, an orientation toward short-term mating was associated with suppressed sexual disgust, but not with pathogen or moral disgust. This relationship held across independent samples, was robust to substantial modifications of the sexual disgust scale, and was true for both sexes. This provides solid support for our a priori hypothesis that individuals dispositionally oriented toward short-term mating have stably reduced levels of sexual disgust.

Existing research has revealed a connection between state-level sexual arousal and disgust (e.g., Ariely \& Loewenstein, 2006; de Jong et al., 2013; Fleischman, 2014; Stevenson et al., 2011), but this study is the first to empirically demonstrate the theoretically predicted connection between mating strategy and dispositional sexual disgust sensitivity.

\subsection{Mating strategy and pathogen disgust}

At first blush, it seems surprising that mating strategy was unrelated to pathogen disgust. Pathogens and sexually transmitted infections are an important potential cost of short-term mating (e.g. Buss, 2012; National Center for HIV/AIDS, Viral Hepatitis, STD, and TB Prevention, 2011). Why would a proclivity for short-term mating not be associated with reduced levels of pathogen disgust?

A closer examination reveals two reasons for the absence of a relationship between short-term mating and pathogen disgust. First, the construct of pathogen disgust as a whole does include cues that are relevant to short-term mating, such as cues to infection or disease. However, it also contains a variety of cues that have little or no relevance to short-term mating, such as those pertaining to non-parasitic insects, rodents, and spoiled and rotting food. One would therefore expect only a small subset of the entire class of pathogen-relevant cues to trigger reduced desire to engage in short-term mating. The rest of the pathogen cues appear weakly relevant to mating, if at all.

Second, there is a distinction between the construct of pathogen disgust and the current studies' operationalization of this construct, the widely used pathogen sub-scale of the Three Domain Disgust Scale (Tybur et al., 2009, 2012). Perhaps in order to ensure the relative orthogonality of the pathogen and sexual disgust subscales, the pathogen subscale is marked by a general absence of "overlap" cues-cues that would be expected to trigger both sexual and pathogen disgust. As a result, not only does the construct of pathogen disgust include cues that are irrelevant to short-term mating, but the scale for pathogen disgust exacerbates this issue by focusing on "pure pathogen" cues that are unrelated to mating. This combination dilutes whatever true relationship may exist between pathogen disgust and mating strategy, leading to the statistical outcome that mating strategy appears strongly related to sexual disgust, but not at all related, or only weakly related, to pathogen disgust. We expect that an instrument that measured pathogen disgust without limiting scale items to those that do not overlap with sexual disgust would indeed be associated with shortterm mating. 


\subsection{Mating strategy and physical attractiveness}

Our secondary hypothesis was that, consistent with existing theory and research, physical attractiveness would be associated with an orientation toward uncommitted mating among men but not among women. As expected, we found that sex and physical attractiveness interacted to predict short-term mating orientation in both studies; the relationship between physical attractiveness and short-term mating was stronger in men.

However, we also found a weak positive association between women's attractiveness and scores on the SOI-R in study 2 . To further investigate this unexpected association, we explored this relationship for each of the SOI-R's subscales. This closer analysis revealed that the link between women's physical attractiveness and their SOI-R scores was driven exclusively by the behavior subscale; there was no relationship in either study between women's attractiveness and their attitudes toward or desire for short-term mating.

This pattern may be revealing, as high scores on distinct subscales have different implications. Physically attractive women may have a larger number of sexual partners (and hence have higher scores on the Behavior subscale) simply because they have a larger number of eager suitors, but not necessarily because they are pursuing a shortterm mating strategy. The fact that women's attractiveness was not associated with desire for or positive attitudes toward short-term mating in either study corroborates this proposition. This absence of a connection between women's attractiveness and short-term mating psychology suggests not that physical attractiveness activates shortterm mating among women, but rather that physically attractive women accumulate a larger number of sex partners, perhaps as a side effect of having a larger number of suitors or by commencing sex at an earlier age.

Indeed, previous studies have typically found either 1) no association between women's physical attractiveness (or proxies thereof) and preferred mating strategy (e.g. Gangestad \& Simpson, 2000; Landolt, Lalumière, \& Quinsey, 1995), or 2) a relationship between women's physical attractiveness and exclusively behavioral indices of mating strategy such as number of sex partners or age at first sex (e.g. Hughes, Dispenza, \& Gallup, 2004; Rhodes et al., 2005; Wiederman \& Hurst, 1998). Some studies have found an association between female physical attractiveness and overall mating strategy (e.g. Clark, 2004), but as the present study reveals, it is possible for such an association to be driven entirely by the behavioral subscale of the SOI-R.

In sum, extant data suggest that physical attractiveness in women may predict behavioral indices of short-term mating such as age at first sex or number of sex partners, but offer no discriminative evidence that physical attractiveness in women activates the pursuit of a shortterm mating strategy. Rather, the subscale-specific nature of this relationship suggests that attractive women's higher scores on behavioral indices of mating activity may be more plausibly accounted for by alternative explanations, such as merely having a greater number of opportunities to mate with high mate value men.

As expected, both studies revealed that the relationship between physical attractiveness and short-term mating was stronger among men. Not only was men's attractiveness directly related to overall short-term mating disposition in both samples, but unlike women, this relationship applied to both the behavioral and attitudinal domains.

The absence of a relationship between men's physical attractiveness and their self-reported desire for short-term mating remains open to interpretation. If increased conscious desire for short-term mating is not necessary for physically attractive men to secure a larger number of sex partners, then behavioral attempts at short-term mating without increased desire could enable short-term mating success while simultaneously avoiding the reputational costs of appearing overly desirous of sex. Alternatively, physically attractive men may accumulate more sex partners partly because women more often initiate sex with attractive rather than unattractive men, though this explanation cannot account for the attitude finding. The results presented here cannot conclusively adjudicate between these (non-mutually exclusive) alternatives, so this remains an important question for future research.

At present, we can conclude that physical attractiveness is positively associated with short-term mating among men, with the strongest effect sizes found for manifest behavior and with partial activation of men's short-term mating psychology.

\subsection{Limitations and future directions}

\subsubsection{Causation and directionality}

It seems reasonable to conceptualize sexual disgust as a design feature of short-term mating strategies, whereas the reverse conceptualization is more problematic: it is not evolutionarily sensible to regard a short-term mating strategy as a design feature of sexual disgust. Our reasoning therefore suggests that the link between mating strategy and sexual disgust is directional in nature, with mating strategy calibrating sexual disgust sensitivity, but of course conclusive inferences about causation await experimental tests.

Two important questions for future research concern the nature of the causal relationships between sexual disgust and mating strategy. First, if mating strategy calibrates sexual disgust, we can ask whether lifespan shifts in mating strategy cause shifts in sexual disgust thresholds. Second, we can ask the reverse causal question. If down-regulated sexual disgust facilitates short-term mating, then inducing sexual disgust may suppress interest in short-term mating, affecting, for example, participants' selfreported sociosexual orientation or ideal number of sex partners. New research can investigate these questions through experimental studies that manipulate mating strategy or sexual disgust, and through longitudinal studies that track whether naturally occurring shifts in mating strategy across the lifespan are accompanied by shifts in thresholds for sexual disgust.

\subsubsection{Physical attractiveness and short-term mating}

Another unresolved puzzle concerns the means by which physical attractiveness leads to short-term mating. Is the mind designed to activate short-term mating strategies partly on the basis of high levels of physical attractiveness, or do physically attractive people simply accumulate more sex partners as an incidental side effect of factors such as having a larger number of suitors or earlier sexual debut? Uncovering the means by which physical attractiveness leads to shortterm mating behavior in men and women remains an important question for future research.

\subsubsection{Replications with different samples and convergent methods}

Our pattern of results was robust across two independent studies and using both the original and modified versions of the sexual disgust scale. This enhances confidence in the veracity of our findings, but the present research is limited by its sample and its method. Our central hypothesis-that reduced sexual disgust is a design feature of successful short-term mating strategies-has yet to be tested in non-western, nonstudent populations or with different methods. Showing that these results generalize to different cultures and replicate using convergent methods will bolster support for this hypothesis.

\subsubsection{Sexual disgust and long-term mating}

This research addresses the relationship between sexual disgust and short-term mating, but has yet to investigate a potential link between sexual disgust and long-term mating. The SOI-R, the instrument most commonly used to assess mating strategy, is a unidimensional scale that taps short-term mating orientation but does not index desire for, or orientation toward, long-term mating (Jackson \& Kirkpatrick, 2007). As such, limitations on the scales used in the current study prevent us from revealing a possible link between sexual disgust and long-term mating. This remains an important avenue for future research, especially 
for testing the idea that comparatively high levels of sexual disgust may actually benefit long-term monogamous relationships.

\section{Conclusion}

A robust pattern of evidence confirmed our primary hypothesis: short-term mating orientation is associated with reduced sexual disgust sensitivity, but not lower levels of pathogen or moral disgust. This central finding held across two independent samples, was robust to modification of the scales involved, and was true for both sexes. This represents the first evidence of a relationship between dispositional mating strategy and disgust, building a potentially important bridge between these two areas of human psychology.

We found qualified support for the secondary hypothesis that physical attractiveness activates the pursuit of short-term mating among men but not among women. As expected, and consistent with previous research, the association between physical attractiveness and shortterm mating was stronger in men, but a weak association was also present among women. Specific analyses further investigating this unexpected finding revealed a previously undiscovered pattern of results that raise questions about the means by which physical attractiveness leads to short-term mating among both men and women. This remains an important question for future research.

The studies presented here reveal strong preliminary support for the central hypothesis that mating strategy calibrates sexual disgust, and invite further tests of the hypothesis using different samples and methods. The novel discoveries revealed by these studies highlight the predictive power and heuristic value of an evolutionary psychological framework for investigating previously unexplored links between disgust and human mating, and point to new research questions for the integration of these domains of scientific inquiry.

\section{References}

Al-Shawaf, L., \& Lewis, D. M. G. (2013). Exposed intestines and contaminated cooks: Sex, stress, \& satiation predict disgust sensitivity. Personality and Individual Differences, 54, 698-702.

Angyal, A. (1941). Disgust and related aversions. The Journal of Abnormal and Social Psychology, 36(3), 393-412.

Ariely, D., \& Loewenstein, G. (2006). The heat of the moment: The effect of sexual arousal on sexual decision making. Journal of Behavioral Decision Making, 19(2), 87-98.

Borg, C., \& de Jong, P. J. (2012). Feelings of disgust and disgust-induced avoidance weaken following induced sexual arousal in women. PloS one, 7(9), e44111, http://dx.doi.org/ 10.1371/journal.pone.0044111.

Buss, D. M. (2003). The evolution of desire: Strategies of human mating. New York: Basic Books.

Buss, D. M. (2012). Evolutionary psychology: The new science of the mind (4th ed.). Boston: Allyn \& Bacon.

Buss, D. M., \& Schmitt, D. P. (1993). Sexual strategies theory: An evolutionary perspective on human mating. Psychological Review, 100, 204-232.

Clark, A. P. (2004). Self-perceived attractiveness and masculinization predict women's sociosexuality. Evolution and Human Behavior, 25(2), 113-124.

Curtis, V., Aunger, R., \& Rabie, T. (2004). Evidence that disgust evolved to protect from risk of disease. Proceedings-Royal Society of London Biological Sciences, 271, S131-S133.

Curtis, V., de Barra, M., \& Aunger, R. (2011). Disgust as an adaptive system for disease avoidance behaviour. Philosophical Transactions of the Royal Society, B: Biological Sciences, 366(1563), 389-401.

de Jong, P. J., van Overveld, M., \& Borg, C. (2013). Giving in to arousal or staying stuck in disgust? Disgust-based mechanisms in sex and sexual dysfunction. Journal of Sex Research, 50(3-4), 247-262.

Fessler, D. M., \& Navarrete, C. D. (2003). Domain-specific variation in disgust sensitivity across the menstrual cycle. Evolution and Human Behavior, 24(6), 406-417.

Fessler, D. M., \& Navarrete, C. D. (2005). The effect of age on death disgust: Challenges to terror management perspectives. Evolutionary Psychology, 3, 279-296.

Fessler, D. M., Pillsworth, E. G., \& Flamson, T. J. (2004). Angry men and disgusted women: An evolutionary approach to the influence of emotions on risk taking. Organizational Behavior and Human Decision Processes, 95(1), 107-123.

Fleischman, D. S. (2014). Women's disgust adaptations. Evolutionary Perspectives on Human Sexual Psychology and Behavior (pp. 277-296). Springer: New York.
Fleischman, D. S., \& Fessler, D. M. (2011). Progesterone's effects on the psychology of disease avoidance: Support for the compensatory behavioral prophylaxis hypothesis. Hormones and Behavior, 59(2), 271-275.

Gangestad, S. W., \& Simpson, J. A. (1990). Toward an evolutionary history of female sociosexual variation. Journal of Personality, 58(1), 69-96.

Gangestad, S. W., \& Simpson, J. A. (2000). The evolution of human mating: Trade-offs and strategic pluralism. Behavioral and Brain Sciences, 23(4), 573-587.

Goldberg, L. R., Johnson, J. A., Eber, H. W., Hogan, R., Ashton, M. C., Cloninger, C. R., et al. (2006). The international personality item pool and the future of public-domain personality measures. Journal of Research in Personality, 40(1), 84-96.

Haidt, J., McCauley, C., \& Rozin, P. (1994). Individual differences in sensitivity to disgust: A scale sampling seven domains of disgust elicitors. Personality and Individual Differences, 16(5), 701-713.

Hughes, S. M., Dispenza, F., \& Gallup, G. G., Jr. (2004). Ratings of voice attractiveness predict sexual behavior and body configuration. Evolution and Human Behavior, 25(5), 295-304.

Jackson, J. J., \& Kirkpatrick, L. A. (2007). The structure and measurement of human mating strategies: Toward a multidimensional model of sociosexuality. Evolution and Human Behavior, 28(6), 382-391.

Johnsen, A., Delhey, K., Schlicht, E., Peters, A., \& Kempenaers, B. (2005). Male sexual attractiveness and parental effort in blue tits: A test of the differential allocation hypothesis. Animal Behaviour, 70(4), 877-888.

Landolt, M. A., Lalumière, M. L., \& Quinsey, V. L. (1995). Sex differences in intra-sex variations in human mating tactics: An evolutionary approach. Ethology and Sociobiology, 16(1), 3-23.

Lee, A. J., Dubbs, S. L., Von Hippel, W., Brooks, R. C., \& Zietsch, B. P. (2014). A multivariate approach to human mate preferences. Evolution and Human Behavior, 35(3), 193-203.

Lieberman, D., Tooby, J., \& Cosmides, L. (2007). The architecture of human kin detection. Nature, 445, 727-731, http://dx.doi.org/10.1038/nature05510.

Lippa, R. A. (2009). Sex differences in sex drive, sociosexuality, and height across 53 nations: Testing evolutionary and social structural theories. Archives of Sexual Behavior, 38, 631-651.

Marr, D. (1982). Vision: A computational investigation into the human representation and processing of visual information. San Francisco: Freeman.

Møller, A. P. (1994). Symmetrical male sexual ornaments, paternal care, and offspring quality. Behavioral Ecology, 5(2), 188-194.

Møller, A. P., \& Thornhill, R. (1998). Male parental care, differential parental investment by females and sexual selection. Animal Behaviour, 55(6), 1507-1515.

National Center for HIV/AIDS, Viral Hepatitis, STD, and TB Prevention (2011). 10 ways STDs impact women differently from men. Atlanta, GA: Centers for Disease Control and Prevention.

Navarrete, C. D., \& Fessler, D. M. (2006). Disease avoidance and ethnocentrism: The effects of disease vulnerability and disgust sensitivity on intergroup attitudes. Evolution and Human Behavior, 27(4), 270-282

Penke, L., \& Asendorpf, J. B. (2008). Beyond global sociosexual orientations: A more differentiated look at sociosexuality and its effects on courtship and romantic relationships. Journal of Personality and Social Psychology, 95(5), 1113-1135.

Rhodes, G., Simmons, L. W., \& Peters, M. (2005). Attractiveness and sexual behavior: Does attractiveness enhance mating success? Evolution and Human Behavior, 26(2), 186-201.

Rozin, P., \& Fallon, A. E. (1987). A perspective on disgust. Psychological Review, 94(1), 23-41.

Schaller, M., Miller, G. E., Gervais, W. M., Yager, S., \& Chen, E. (2010). Mere visual perception of other people's disease symptoms facilitates a more aggressive immune response. Psychological Science, 21(5), 649-652.

Stevenson, R. J., Case, T. I., \& Oaten, M. J. (2011). Effect of self-reported sexual arousal on responses to sex-related and non-sex-related disgust cues. Archives of Sexual Behavior, 40(1), 79-85.

Sugiyama, L. (2005). Physical attractiveness in adaptationist perspective. In D. M. Buss (Ed.), The handbook of evolutionary psychology (pp. 292-342). New York: Wiley.

Symons, D. (1979). The evolution of human sexuality. New York: Oxford University Press. Symons, D. (1995). Beauty is in the adaptations of the beholder: The evolutionary psychology of human female sexual attractiveness. In P. R. Abramson, \& S. D. Pinkerton (Eds.), Sexual nature/sexual culture (pp. 80-118). Chicago: University of Chicago Press.

Tooby, J., Cosmides, L., Sell, A., Lieberman, D., \& Sznycer, D. (2008). Internal regulatory variables and the design of human motivation: A computational and evolutionary approach. In Andrew J. Elliot (Ed.), Handbook of approach and avoidance motivation (pp. 251-271). Mahwah, NJ: Lawrence Erlbaum Associates.

Trivers, R. L. (1972). Parental investment and sexual selection. In B. Campbell (Ed.), Sexual selection and the descent of man: 1871-1971 (pp. 136-179). Chicago, IL: Aldine.

Tybur, J. M., \& Gangestad, S. W. (2011). Mate preferences and infectious disease: Theoretical considerations and evidence in humans. Philosophical Transactions of the Royal Society, B: Biological Sciences, 366(1583), 3375-3388.

Tybur, J. M., Lieberman, D., \& Griskevicius, V. (2009). Microbes, mating, and morality: Individual differences in three functional domains of disgust. Journal of Personality and Social Psychology, 97(1), 103-122.

Tybur, J. M., Lieberman, D., Kurzban, R., \& DeScioli, P. (2012). Disgust: Evolved function and structure. Psychological Review, 120, 65-84

Wiederman, M. W., \& Hurst, S. R. (1998). Body size, physical attractiveness, and body image among young adult women: Relationships to sexual experience and sexual esteem. Journal of Sex Research, 35(3), 272-281. 